\title{
DOES SITUATIONAL CRIME PREVENTION REQUIRE A RATIONAL OFFENDER?
}

\author{
Richard Wortley \\ Nick Tilley \\ UCL
}

\author{
Corresponding author: \\ Richard Wortley \\ Jill Dando Institute of Security \& Crime Science \\ University College London \\ r.wortley@ucl.ac.uk
}




\begin{abstract}
Opportunity preceded choice and choice preceded rational choice in the development of situational crime prevention theory. Rational choice was, thus, a post hoc theoretical supplement to the initial realisation that immediate situations furnish key conditions affecting criminal behaviour and that these situations could be modified for preventive purposes. Rational choice seemed to suggest a general mechanism that could link the situation to the act. Change the situation and the rational choices about what to do will also change. The disposition to offend is not so strong that individuals' criminal behaviours are inexorable. Choice in general and rational choice in particular filled for a while a theoretical vacuum to make sense of the influence situations evidently exert on behaviour and has been used to inform further research. It also provided a heuristic for practitioners to think about changes to the situation that might influence prospective offenders' decisions. Yet there is growing evidence that rational choice assumptions are implausible and unnecessary. They may now be inhibiting rather than facilitating progress in research and practice. Their weaknesses may also be detracting from the credibility of situational crime prevention more generally, both in academic and practitioner circles. It is argued here that theory and practice would both be improved by abandoning rational choice as the sole theoretical foundation for situational crime prevention. In its place, we outline ten tenets, which we argue more fully describe the role situations play in crime, and provide a framework for accommodating a wide range of situational theories and perspectives.
\end{abstract}


Key words: rational choice perspective; situational crime prevention; environmental criminology; offender decision-making 
Thomas Kuhn (1962) and Imre Lakatos (1978) show that major scientific ideas rarely perish at a stroke. Despite Popper's (1959) emphasis on falsification, theories can be readily and rationally preserved by ad hoc adaptations, and qualifications that effectively inoculate them from attack. Moreover, as even Popper himself conceded, this often makes good sense for the advancement of science. Theories would perish before their potential was realised if they were jettisoned at the first sign of trouble. The full articulation of a theory takes time. Initial formulations can be crude. Moreover, even when a theory begins to fail when 'anomalies' as Kuhn describes them appear - in the natural sciences that has not marked the point at which confidence in existing paradigms is lost and something new sought.

Lakatos refers to 'progressive problem shifts' to describe adaptations to theories that are fruitful in that they produce new findings. He refers to 'degenerating problem shifts' that preserve a theory but are not progressive and do not generate new findings. For Kuhn, the accumulation of anomalies leads eventually to a crisis of confidence and the pursuit of a new paradigm. Lakatos' formulation is less rooted in 'mob psychology' and refers instead to a change of direction that makes sense for the advancement of knowledge.

We use a Kuhnian/Lakatosian framework as a way of interpreting the history of situational crime prevention (SCP), the importation of the rational choice perspective (RCP) into it, criticisms of situational crime prevention that focus on RCP, and responses to those criticisms. We argue that even if it was once helpful, RCP will no longer do as a fundamental underpinning of SCP and is now holding it back. We conclude with a new set of 10 tenets for SCP that no longer makes RCP central. Our aim is not to propose a new theory for SCP but 
rather to describe the role that situations play in behaviour in a way that accommodates multiple theoretical perspectives. This, we suggest, offers a fruitful way ahead both for research on crime and for policy and practice to address crime problems.

\section{HOW RCP CAME TO BE ASSOCIATED WITH SCP}

While RCP and SCP have become closely linked, this has not always been the case. The ideas behind SCP began coalescing into coherent prevention models from the beginning of the 1970s. RCP on the other hand was first proposed as a foundation for SCP some 15 years later. In other words, RCP was settled on as an explanation for SCP practices that were already well established. It was intended to add theoretical coherence to SCP and to inform a research programme. It was seen, therefore, to comprise a progressive move.

The first proto-situational models of crime prevention were presented in two books, with strikingly similar titles, published within a year of each other. The first was C. Ray Jeffrey's (1971) Crime Prevention Through Environmental Design; the second was Oscar Newman's (1972) Defensible Space: Crime Prevention Through Urban Design. As their titles suggest both books proposed crime control strategies that involved manipulation of the immediate environment. Their approaches and underpinning assumptions, however, varied considerably.

Jeffrey, a criminologist, built his situational analysis of crime around an operant conditioning model of behaviour. With this as his starting point, he proposed an eclectic assortment of interventions designed to alter the punishment and reward structures in criminogenic environments. His approach 
shares some assumptions with RCP, inasmuch as the performance of crime was seen to be a function of its consequences. Crime prevention, therefore, was seen to involve the manipulation of those consequences - behaviour that was rewarded would be repeated while behaviour that was punished would be discouraged. However, Jeffery's was a Skinnerian, black-box model of human behaviour. There was no place for cognition, much less rational decision making. It was also highly deterministic. 'There are no criminals' Jeffrey declared, 'only environmental circumstances that result in criminal behaviour. Given the proper environmental structure, anyone will be criminal or non-criminal' (Jeffrey, 1977, p. 177).

In contrast, Newman, an architect, barely mentioned offenders. The central construct in his approach was territoriality. Territoriality is the tendency to lay claim to an area and defend it against intruders, and it is a quality possessed by territorial possessors not intruders. Thus, Newman's focus was on changing the behaviour of non-offenders - the potential victims and observers of crime. Operating at the urban design level, Newman's interventions were formulated to instil a sense of ownership in residents. If residents took a greater proprietorial interest in their immediate environs, it was argued, then they would also exercise greater levels of care and surveillance over those areas. As for the psychological processes acting on potential offenders, implicit but never fully fleshed out was a rudimentary deterrence theory. Offenders need only possess the capacity to recognise territorial cues - boundary markers, changes in paving texture, signs of occupation, and the like - that signalled that an area was under the care and control of residents. With this realisation it was assumed that they would decide that it was too risky to offend. 
Early writings by Ronald Clarke, the chief architect of SCP, predate those of Jeffrey and Newman. In 1967 he published a research paper on absconding from a residential school for juvenile delinquents. Clarke noted that the best predictors of absconding were aspects of the environment - hours of daylight, features of the school's regime, the distance home - and not any individual factors associated with the absconders. At this point Clarke provided little in the way of theoretical analysis of why the environment was so important or how it interacted with characteristics of the individual. Further situationally-focused papers followed (Clarke and Martin, 1971; Sinclair and Clarke, 1973) but it was not until the publication of Crime as Opportunity, the foundational Home Office report that in 1976 marked the first manifesto for situational crime prevention (Mayhew, Clarke, Sturman and Hough, 1976), that the question of underpinning general theories arose. Crime as Opportunity emphasised that criminal behaviour is responsive to situational cues. Gibbons (1971) is quoted approvingly in it, when he refers to 'deviance (as) a temporal response to provocations, attractions and opportunities of the immediate situation' (Mayhew et al 1976: 1, italics added). A subheading refers to 'situational inducements to criminality' (ibid: 2). These classes of cue countenance various ways in which situations may encourage criminality. At this point, there was no mention of 'choice'.

Choice - but not rational choice - was central to Clarke's 1980 paper in the British Journal of Criminology (BJC), which laid the first systematic academic foundations for situational crime prevention theory. Indeed, one of the headings there is 'Crime as the Outcome of Choice' (Clarke 1980: 161). The BJC paper is pitched against common sense and criminological dispositional theories, which prevailed then and continue to thrive in folk thinking about crime, which 
construe criminality and the consequential criminal acts as the product of some more or less aberrant or pathological impulse springing from social or personal factors bearing on the offender. Against this, Clarke emphasised that almost always offenders know what they are doing and in this sense there is at least an element of choice in their actions. He noted that even if there are predisposing conditions these are hard to change, especially in the short term. Focusing on the immediate and manipulable conditions in which crime commission choices are made (even if those choices are influenced by social or personal factors), however, suggests a practical agenda for preventing crime. Clarke listed a range of conditions that might influence choices to offend, of many of which, he conceded, the offender may be unaware. These include the offender's motives, mood, moral judgements, criminal knowledge and perceptions of opportunities, assessments of risk and likely consequences of offending, and the likelihood that s/he has been drinking. Clarke said of them that, 'These separate components of subjective state and thought processes which play a part in the decision to commit a crime will be influenced by the immediate situational variables...'

(Clarke 1980: 161). Hence, in 1980 Clarke's articulation of SCP theory embraced the 'choice' element of RCP but not the 'rational' one.

The first fully-fledged exposition of the Rational Choice Perspective as we now know it came in a paper published by Clarke with Derek Cornish five years later (Clarke and Cornish, 1985). Clarke and Cornish presented a detailed and wide-ranging review of then recent developments in the sociology, criminology, economics and psychology of crime. They referred to the sociology of deviance, ecological studies of criminal activity, criminal careers research, and applications of cognitive psychology and economics to offender decision-making, all of which 
were rejecting pathological explanations of crime and emphasising the need to understand offenders' perspectives. With regard to accounts of crime that stress the immediate environment, Clarke and Cornish counselled against deterministic models of the offender as a passive object of situational causes. The concept of rational choice was proposed as a way of drawing together these disparate threads into a single explanatory model while retaining a view of the offender as an active agent.

Clarke and Cornish did not invent rational choice but rather adapted an existing concept to suit their needs. The roots of rational choice models of crime can be found in the utilitarian deterrence models of Beccaria and Bentham in the late eighteenth century, while formal rational choice theories were already built into classical economics and had been applied in psychology and sociology (Becker, 1957, 1960; Blau, 1964; Coleman, 1973; Homans, 1961; Kahneman and Tversky, 1973; von Neumann and Morgenstern, 1942; Savage, 1954; Simon, 1957). The insight Clarke and Cornish brought from rational choice was the understanding that much of the information about the likely costs of crime was located in the immediate crime setting, as opposed to the more distant machinery of the criminal justice system (the focus of Beccaria and Bentham). In later writings, Cornish and Clarke imply that their decision to settle on RCP as a conceptual framework was made in part on pragmatic grounds because it was thought to be a more palatable explanation for a criminological audience than the deterministic operant conditioning model, with which it shares the basic assumption that behaviour is governed by its consequences (e.g., Cornish and Clarke, 2008). 
There are two crucial points to be made about RCP as proposed by Clarke and Cornish - points far too often overlooked by subsequent critics and devotees alike. The first is that rational choice was presented in highly qualified terms. From the start Clarke and Cornish understood that rationality is constrained, and their approach owes a particular debt to Simon's (1957) concept of 'bounded' rationality. Simon argued that human decision-making was neither perfectly rational nor wholly irrational, but rather 'satisficing' - satisfactory and sufficient. The rational decision making process may be affected by cognitive biases, lack of information, time pressures, emotional arousal, individual values, and a range of other factors. The utility of an anticipated outcome, therefore, is subjective judged from the decision-maker's point of view - and an individual may not always pursue a course of action that ultimately produces the greatest benefits. In accordance with this, Clarke and Cornish conceded that the rationality of rational choice in criminal behaviour is highly circumscribed. It would be implausible, they acknowledge, to suggest that at every turn offenders make calculations on expected outcomes or that information is sought and obtained on which to make informed calculations about whether to offend, how to offend, and where and when to offend.

Second, Clarke and Cornish presented RCP as a model for practice: it was never intended as a detailed and accurate description of how offenders actually make decisions (see Wortley, 2013). Their aim was to provide a simplified account of the role of situations in crime that would guide research and policy. While RCP is often referred to as rational choice theory in the literature, they have never done so; the term 'perspective' was chosen advisedly. They regarded RCP as a heuristic for synthesising existing research, for giving direction to 
future research, for analysing existing policy and for finding out fruitful future crime control initiatives. In other words it served to stimulate the research program for situational crime prevention as well as to enhance practice in relation to its immediate progenitors: it was thus conceived as a progressive problem-shift. Repeatedly throughout their 1985 paper (and consistently in later writings) they refer to RCP as merely 'good enough' to explain the processes of criminal involvement and the occurrence of criminal events. The stripped-down, one-dimensional depiction of the offender - 'bereft of moral scruples' and 'without any deficits such as lack of self control' - was also deliberate in order to avoid cluttering the model with unnecessary detail 'that might get in the way of rational action' (Cornish and Clarke, 2008, p. 39). Moreover, they explicitly invited further developments of their decision-making models in the light of future research. Their rational choice models were 'tentative' (p. 163), 'still at a relatively early stage' (p. 163), 'a useful starting point' (p. 178), 'temporary, incomplete, and subject to continual revision' (p. 178), and to be 'modified or discarded' (p. 149) when no longer fit for purpose (Clarke and Cornish, 1985).

RCP was seen by Clarke and Cornish in the mid 1980s as good enough to underpin both research and practice in SCP. SCP had always been conceived as a scientific research programme and a policy/practice programme. Rational choice was deemed helpful to both. It could inform a programme of research better to understand criminal behaviour, avoiding traditional and dubious assumptions about crime as a product of special pathological people with aberrant personalities, genes or social backgrounds, and focusing instead on the normality of crime as an intelligible response to immediate cues by ordinary people 
pursuing their interests as best they can. It could inform policy and practice by steering decision-makers to practical ways in which they could alter the balance of advantage offered for criminal acts in the specific circumstances in which they occurred.

\section{THE PROBLEMS WITH RCP}

It should be clear by now that RCP was a theoretical port of convenience for SCP, co-opted post hoc for pragmatic reasons - a building block for a progressive research programme and policy paradigm. SCP was not derived from RCP nor is RCP necessary for it. Despite this, RCP and SCP have typically come to be viewed as inextricably linked. For devotees of the situational perspective, RCP is deemed to provide a model of the offender that explains how and why situations cause crime and that informs the development of situational strategies designed to inhibit criminal responses. For critics of the situational perspective, RCP has provided a convenient straw man to be knocked down in order to disparage the field more generally: SCP depends upon RCP; offenders aren't rational; therefore SCP is invalid.

Until recently, criticisms of RCP have come largely from those antipathetic to the situational perspective challenging its account of why offenders commit crime - those who would ditch the situational paradigm entirely. However, there is an increasing number of critiques of RCP from those within or sympathetic to the situational perspective (Bouhana, 2013; Ekblom, 2007; Laycock and Pease, 2012; Nee and Ward, 2014; Sidebottom and Tilley, forthcoming; van Gelder, Elffers, Reynald and Nagin, 2014b; Wikström and Treiber, 2015; Wortley, 1997, $2001,2012,2013)$. These critiques have questioned not just the adequacy of RCP 
as a theoretical model of offending behaviour, but increasingly, too, the extent to which it provides a sufficient underpinning for SCP. These critics, with whom we identify here, take rational choice to hamper the broader research and practice programme of SCP - to mark a degenerating problem-shift inhibiting further progress.

There are three main theoretical criticisms levelled at RCP - that human decision making is as much characterised by cognitive errors and biases as it is by rationality; that the emphasis on cognition overlooks the role that personal factors such as emotions and dispositions play in human behaviour; and that a great deal of behaviour is the result of automatic cognitions that occur below the level of conscious awareness (see Wortley, 2013). In fact, each of these criticisms was addressed by Clarke and Cornish in their original 1985 paper where they were at pains to emphasise the constraints on human rationality. It is easy to show that offenders are not perfectly rational (e.g., Hayward, 2007; Katz 1988; Trasler, 1986), but then Clarke and Cornish have never said that they are. Likewise, Clarke and Cornish readily conceded that decisions made in the heat of the moment are sub-optimal, and that over time many crimes are committed routinely on the basis of 'standing decisions'. Thus most criticisms of RCP can be effectively countered by labelling them as 'misconceptions' or 'misperceptions' and simply referring back to the original, highly qualified description of the model (Clarke, 2005; Cornish and Clarke, 2008).

However, relying on the 'good enough' ambitions of RCP as a defence presents a double-edged sword for those interested in advancing SCP. On the one hand, the concept of bounded rationality provides flexibility and a capacity to accommodate anomalies, effectively inoculating RCP against falsification. On the 
other hand, the qualification that rationality is bounded comes at a price and exposes the theoretical limits of RCP. Each concession of impaired rationality reduces the explanatory power of the model. For example, the concession that an offender under high levels of emotional arousal makes less rational decisions than an offender not so aroused can be easily accommodated within RCP, but doing so reduces rationality to a partial explanation.

Working with a qualified model of rationality might not be such a problem if there were also an active research programme examining the situational conditions under which rationality is impaired and the impact of the impaired rationality on offenders' decisions, but there is not. Despite Clarke and Cornish's explicit invitation to researchers to modify their decision-making models in the light of new evidence, RCP today remains essentially as it was presented in 1985, largely unaffected by the theoretical advances that have taken place elsewhere in the cognitive sciences (Wortley, 2013). The expected progressive problem-shift has not materialised. The concept of 'bounded' rationality has inadvertently inhibited further research on offender decision-making by providing a convenient escape clause. The factors that limit rationality can be treated as unfortunate 'noise', interfering with, but not completely eliminating, the rational choice process. In the case of emotional arousal, for example, the response to the criticism that RCP does not account for so-called expressive crimes typically stresses the vestiges of rationality that remain even in highly aroused offenders (e.g., R. Felson, 2005), with little consideration given to the ways in which arousal affects decision making or why the offender may be so aroused in this situation (see Katz, 1988). In Lakatos's terms, adherence to RCP in such cases as an essential element of SCP is degenerative as a research programme. The non- 
rational elements are treated as anomalous, to be conceded but set aside, as Kuhn shows also occurs in the history of the natural sciences.

RCP as a theory for practice is similarly to be found wanting. RCP frames the crime prevention task in terms of opportunity reduction. However, there are many SCP strategies that do not involve plain reduction in opportunity. Indeed, the sequence of typologies of situational crime prevention techniques that Clarke and Cornish have devised have changed in significant ways that tacitly acknowledge the limits to rational choice without explicitly recognising that they show the inadequacy of the supposed rational choice foundations of situational crime prevention. The version of the typology in Clarke's introduction to the first edition of his collection, Situational Crime Prevention: Successful Case Studies, included columns headed 'increasing the effort', 'increasing the risks', and 'reducing the rewards' (Clarke 1992), whilst the equivalent columns in the same table in his introduction to the second edition referred to 'increased perceived effort', 'increased perceived risks', and 'reducing anticipated rewards' (Clarke, 1997). These changes acknowledge the subjective nature of the judgements involved in offending decisions. The second edition also added a further column headed 'removing excuses' (ibid), in recognition that ethical considerations could modify a simple cost-benefit calculation by the prospective offender. Later still, the strategy 'reducing provocations' recognised that situational factors can precipitate crimes that the offender may not have otherwise contemplated, albeit that in that version of the table of techniques references to 'perceived' and 'anticipated' in relation to effort, risks and rewards are no longer present (Cornish and Clarke 2003: 90). The addition of excuse-removal and provocationreduction can only be incorporated into RCP by making it tautologous and 
depriving it of its distinctive analytic bite. Moreover, the notion of provocations undermines the RCP notion that preferences are consistent. In economics too, 'hyperbolic discounting' (the systematic tendency of humans to switch preference orders as the moment of decision-making becomes imminent) undermines any expectation of consistent intentions and preferences in ways highly relevant to decisions over the commission of crimes (see Elster 2007: 111-123). Homo economicus, the cool, though fallible, calculator of personal utilities, can no longer be assumed adequately to represent the potential offender, who instead becomes subject to moral restraint and emotional drives.

Even those prevention strategies that do involve opportunity reduction do not necessarily involve the exercise of rational choice. In many cases reducing opportunity does not affect the choices that potential offenders make but reduces the choices that are available to them (Sidebottom and Tilley, forthcoming). Taking your laptop with you when you park your car rather than leaving it on the back seat ('removing targets') does not reduce the perceived rewards of offending in any meaningful cost-benefit sense; it simply eliminates theft of your laptop as an option. The invocation of any rational choice deliberation does not arise. In a similar way, offenders cannot commit crime, no matter how motivated they might be to do so, if they lack the necessary physical or personal resources (Ekblom and Tilley, 2000). Burglary through a second storey window may not be possible if there is no ladder handy ('controlling tools and weapons') or if the offender is afraid of heights. There are countless similar examples where what matters is the supply of options, rather than the reasons for exercising choice. 
There are two ways of responding to the limitations of RCP. The first is to retain the cognitive choice framework but look to elaborating it to account for current deficiencies. In other words, treat individual, utility-maximising rational choice as the default, but create a more nuanced version of the offender which is attentive to the ways in which crime-commission decisions that might otherwise be rational may be compromised or limited by the internal cognitive limitations and external influences already alluded to by Cornish and Clarke. This would preserve RCP as a core element of SCP and try to sweep in non-rational elements on the grounds that the non-rational elements comprise challenging 'puzzles' (to borrow a term used by Kuhn to describe 'normal science' occurring under the auspices of given 'paradigm'), but do not furnish grounds for any fundamental change.

A recent example of this approach is the edited volume Affect and Cognition in Criminal Decision Making by van Gelder, Elffers, Reynald and Nagin (2014a), in which Clarke has a chapter. Contributors were invited to draw on advances in the cognitive sciences to provide a more contemporary, complete, and scientifically rigorous account of the role of emotion in offender decision-making than that provided by RCP. In their introductory chapter, the editors clearly indicate that they have no intention of abandoning a choice model of offending. They frame their task in terms of giving due attention to the 'bounded' nature of rationality, which has been neglected over the years. "Rather than referring to the 'introduction' of affect into rational choice theory and models of criminal decision making" they write, "it would perhaps be more accurate to refer to 'reinstating' the role of affect in criminal decision theory" (van Gelder et al, 2014b, p. 12). 
The second way of responding to the limitations of RCP is to abandon the cognitive choice model as the default and seek a fresh way of conceptualising the role of situations in behaviour. This is the path we take in this paper. We take the SCP programme as it incorporates RCP to be degenerating, as it is adapted to accommodate non-rational aspects criminal activity (and inactivity) and the situations providing for these non-rational drivers. Abandoning RCP as the primary underpinning for SCP, we argue, will open the door to new directions in research on situational generators of crime and in crime prevention practice. We conceive of it as a progressive move. In all this it is important to remember, as we have been at pains to stress already, that the situational account of crime predated the incorporation of RCP, that there have been alternative assumptions about the underlying relationship between situational and criminal activity, and that boundedness has always been emphasised in RCP as it relates to criminal activity. Rejecting RCP is very different from rejecting SCP.

\section{WAYS OF UNDERSTANDING THE PERSON-SITUATION RELATIONSHIP}

Ultimately the validity of the situational perspective rests on the premise that immediate environments play a non-trivial role in influencing behaviour. The respective contribution to behaviour of an individual's dispositions, on the one hand, and the context in which that behaviour occurs, on the other, has been a long-standing point of contention in the social sciences, the basis of the so-called person-situation debate (Mischel, 1968). The issue we examine in this section is not whether crime is, at least in part, a consequence of situational factors something that we take to be axiomatic - but how well RCP accounts for the effect of these situational influences. To do this, we outline three ways in which 
the person-situation debate has been framed in the literature. For some in the social sciences, the issue is seen as a contest between situational and dispositional accounts of behaviour: either one or the other plays the dominant role. For others, the interest lies in how the person and the situation interact with one another. The person-situation interaction, in turn, has two interpretations (see Wortley, 2012). One is that there is a reciprocal relationship in which individuals both affect, and are affected by, their immediate environment. The other is that behaviour is the combined outcome of situational and dispositional factors. We argue that in all three cases RCP fails to provide a full account of the role of situations.

Social scientists who are interested primarily in the effects of the immediate social and physical environment on behaviour hold that the effects of particular situations are more or less consistent across a given group or population. Almost everyone attending a funeral will be quiet and reverential; those same people attending a wedding may be rowdy and joyous. Variations in behaviour are caused by variations in the environment rather than by factors within the individual. RCP emerged as one account of how this could be the case. The probability of crime varies by situation, providing those within it prospects of utilities that, ceteris paribus, they maximise. With its bare-boned depiction of the offender, no attention is paid to variations among individuals. Humans are defined by a single, universal attribute - the capacity to make (boundedly) rational choices - that provides the sole mediating process through which environmental contingencies are assessed and translated in to action. However, as we have highlighted, rational decision-making has severe limitations as a mechanism for capturing how we relate to the world around us. Errors in 
reasoning are ordinarily the rule not the exception, while under conditions of emotional arousal decision-making processes are overwhelmed by feelings. Decision-making is not just prone to error but in many cases rationality may not even play a meaningful role in behaviour. Cognitive theorists acknowledge that we are aware of just a tiny fraction of the neuronal activity that occurs within our skulls. A great deal of our behaviour occurs, not as a result of conscious deliberation, but routinely and reflexively as the result of cognitive processes that occur automatically below the level of conscious awareness. Moreover, there is more to human behaviour than decision making. RCP is fundamentally limited by the restricted pallet of human processes it provides to account for the impact of situational forces. It pays little consideration to the broader spectrum of the attributes that define humans - their desires, beliefs, emotions and moral understandings.

At best, then, RCP can provide no more than a partial account of the impact of the immediate environment on the offender. Only the offender's instrumental cognitions come into play. There is little recognition of the power of situations to affect individuals in ways of which they may not be fully aware or over which they may have limited control. Nor is there any sense in RCP that offenders are changed in any fundamental way by their encounters with the immediate environment. We can contrast this narrow rendering of situational effects with the far richer accounts given elsewhere in the social sciences. Solomon Asch (1951), for example, showed how simple expressed judgements of line length are affected by those expressed by others even when clearly contrary to fact. Participants not only offered incorrect answers in order to avoid social censure, many convinced themselves that their incorrect response was correct. In the 
famous Stanford prison experiment (Haney, Banks and Zimbardo, 1973;

Zimbardo, 2007), college students randomly allocated to the role of guards in a mock prison quickly became brutal and authoritarian towards those allocated to prisoner roles. The situational press caused the guards to lose a sense of themselves as individuals as they submerged their identities within the group. In the equally notorious obedience to authority studies (Milgram, 1974), the authority exuded by the experimenter induced nearly two thirds of participants to deliver what they believed to be life-threatening electric shocks to a confederate participant who was purportedly being punished for giving incorrect answers. Participants were able to shift the moral culpability for their actions onto a third party enabling them to engage in what they would normally recognise as reprehensible behaviour. Wortley $(1997 ; 2001)$ summarised some of the alternative mechanisms, apart from rational choice, through which situational factors may influence behaviour. Situations can: prime latent thoughts and emotions; elicit reflexive responses; trigger habitual behaviours; stimulate sexual arousal; create expectancies about how to behave; provide examples to emulate; pressure individuals to conform; pressure individuals to obey; prompt defiance; create a sense of anonymity; reduce the capacity to selfmonitor one's behaviour; obscure moral rules; obscure the consequence of actions; obscure personal responsibility for actions; depersonalise and dehumanise victims; induce frustration; generate stress and heightened emotion; threaten status and esteem; and provoke retaliation.

The person-situation interaction as a reciprocal process is an extension of the situationalism model described above. Again there is generally little interest in variations among individuals. However, this approach recognises that the 
person and the situation engage in a bi-directional and often iterative exchange. Individuals are affected by the situation but they can also alter those situations in an unfolding sequence of responses. Person A bumps person B spilling his drink; person B verbally abuses person A; person A responds in kind; person B pushes person A; and so on. The focus on the bi-directionality of causation emphasises the agency of the actor. The individual is portrayed, not as a passive pawn subject to capricious environmental forces, but as an active and purposive agent capable of changing environments in order to achieve behavioural goals. The iterative nature of the person-situation interaction invites us to consider behaviour, not as an atomised blip in time and space, but in molar terms as the product of a complex series of inter-related events.

It is in the sense of a reciprocal relationship that Cornish and Clarke have in more recent years come to use the term person-situation interaction to describe the underpinning rationale for RCP (e.g., Cornish and Clarke, 2003, 2008). And up to a point RCP is consistent with this model. The immediate environment affects the offender's assessment of the opportunity structures and this in turn determines how he/she will act upon the environment (i.e., by committing or not committing crime). Moreover, from the start Clarke and Cornish have emphasised the purposive, goal-directed nature of offending (Clarke and Cornish, 1985; Cornish and Clarke, 2003, 2008). The default offender is the antisocial predator who seeks out and creates crime opportunities in order to maximise returns and minimise risks. The portrayal of behaviour as an iterative sequence of behaviours is also well captured in RCP in the form of crime scripts, prototypes of which were outlined in the original Clarke and Cornish (1985) paper and later elaborated upon by Cornish (1994). 
Our concern with RCP again relates to the narrowness of its scope. The offender certainly acts upon the environment, but, as we have previously described, the impact of the environment on the offender is highly restricted. It is an interaction wholly on the offender's terms; there is not the two-way street that the term interaction implies. By setting the antisocial predator as the default, RCP explicitly 'downplays any independent effect - such as a motivating one - that exposure to setting factors might have on the offender' (Cornish and Clarke, 2003, p. 59). Offenders are seen arrive at the crime scene already motivated to commit a crime and they are in charge of the effect that the environment has upon them. The situation is merely the provider of data that potential offenders may accept or reject, a process that remains under rational control. Compare this with the profound psychological impact demonstrated by, say, the Stanford prison experiment, where the individuals' very sense of themselves was redefined. Perversely, in its own way RCP perpetuates a view of offenders as internally driven by static criminal motivations, a view which is not much different from that to be found in the familiar dispositional theories of crime.

Finally, the person-situation interaction can refer to an interdependent relationship in which the effect of the situation on behaviour depends upon the characteristics of the particular person in question. Put another way, the nature of the reciprocal interaction described above may not be the same for all people at all times. In this conception, behaviour is a function of the person-and-thesituation, and researchers have a specific interest in the role of individual factors. Interaction is used in the same sense that the term is used in statistics: when a criminally disposed individual enters a criminogenic situation the combined 
effect of the personal and situational factors is greater than the sum of their individual effects.

We can think about variations in offender susceptibility to situations in two ways - as within- and between-individual phenomena. With within-individual variation, a particular individual may be or more or less susceptible to criminogenic influences from one time to another depending upon his/her current psychological functioning. Over the short term, an individual may be more likely to offend in a given situation if they are depressed, for example, than if they are not. Over a longer time span, an individual's susceptibility to crime is likely to change over the life course, following the age-crime curve. With between-individual variation, different individuals are liable to react differently to the same situation. While an act of aggression, for example, may not be a direct expression of a generalised aggressive disposition, a person with aggressive personality traits is likely to be more easily provoked to violence in a given situation than someone without these traits. Likewise the poor and needy as against the rich and privileged, the young as against the old, and men as against women enter the same situations on different terms and are liable to respond in different ways.

RCP has no place for interdependent interactions. Cornish and Clarke make no bones about the fact that within RCP the offender is treated as a cypher, devoid of any personal distinguishing qualities (Cornish and Clarke, 2003, 2008). This is, of course, a gross oversimplification, a fact that Cornish and Clarke readily acknowledge, and the fiction is maintained on pragmatic (rather than theoretical) grounds. It is obvious that not every person who enters a criminogenic situation is at the same risk of offending. A hundred people may 
walk passed an open window before someone decides to climb through and commit burglary. Indeed, the focus in RCP on the antisocial predator as the default offender implicitly recognises this fact. But offenders are by no means all antisocial predators. Once again RCP provides us with a partial explanation and does not offer the structural capacity to bridge personal and situational contributions to crime. As such, it is out of step with contemporary attempts to understand behaviour as a combined consequence of personal and situational factors (Kahle, 1984; Mischel, 2004; Mischel and Shoda, 1995: Ross and Nisbett, 2011), a research direction that might provide a more nuanced and realistic picture of the relationship between offenders and settings of their crimes.

\section{TEN TENETS UNDERPINNING SITUATIONAL CRIME PREVENTION}

Rational choice was only ever 'good enough' for some explanatory purposes. Both in theory and in practice, notably in regard to crime, it is clearly insufficient. Any adequate theory needs to account for diverse ways in which individuals and situations interact to generate patterns, and for crime prevention what matters most is their potential to suggest practical intervention possibilities. Moreover the cost of the unnecessary identification of rational choice theory with situational crime prevention has led many to assume that weaknesses in the former entail weaknesses in the latter. This is a mistake, but remedying it requires some reconceptualisation of the theoretical foundations of SCP.

Given the diversity of mechanisms that may be involved in processing situational inputs, and the different ways that the person-situation relationship may be conceptualised, we do not believe that it is possible to settle on a single theory for SCP that will satisfy everyone. Instead, in this section we set out in 
programmatic terms what we take to be the basic tenets of situational crime prevention theory - propositions that are by and large accepted by most researchers in the field and that provide a framework for accommodating a wide variety of theoretical perspectives, including RCP. They are intended both to provide a more realistic foundation for research on situational influences on criminal behaviour better to analyse problems with a view to identifying potential, realistic crime preventive strategies. There are ten tenets, namely:

\section{The potential to commit crime is widely distributed in the}

\section{population}

Human beings have the capacity for a wide repertoire of behaviour. All are liable to act in ways that have been defined as criminal and almost all adults will commit some criminal acts at some time. It is unhelpful (and inaccurate) to think that the population can be neatly divided into criminals and noncriminals.

\section{There is variation in the potential to commit crime across}

\section{individuals}

Notwithstanding tenet 1 , individuals differ in the strength of their potential to commit crime. Some individuals are strongly predisposed to commit crime; most people are weakly predisposed. There may be many reasons that individuals differ in their potential to commit crime, including the nature of their genetic makeup, developmental influences, and the socio-cultural world in which they are enmeshed. These distal causes of crime are generally beyond the remit of situational interventions, but the fact of these variations among individuals may have implications for the implementation of SCP. 


\section{The potential to commit crime varies over time for the same individual}

The individual potential to commit crime involves both relatively stable characteristics and more transient psychological states. Thus, crime liability is not constant across time for the same person, either in terms of their stage of life or within any stage of their life. The age-crime curve suggests that the potential to commit crime peaks in late adolescence. Similarly, potential may fluctuate across smaller time scales such that there may be spurts of offending interspersed with periods of non-offending.

\section{The likelihood that a given individual will engage in crime varies across situations}

Crime liability is not constant across situations for the same person. Situations vary widely in their potential to activate (or suppress) a given individual's crime potential. Even habitual offenders do not commit crime in every situation they encounter while a normally law-abiding individual may commit an occasional crime under certain circumstances. Crime occurs when an individual meets a situation that activates his/her liability to offend.

\section{The relationship between an individual and the situation is bi- directional and iterative}

Situations affect individuals but individuals also affect situations. A situation may activate a criminal liability and an individual may manipulate the environment to maximise the potential to commit crime. A particular crime event may involve an iterative sequence of person-situation interactions.

6. The likelihood that a given situation will activate a criminal response varies across individuals 
Crime liability is not constant across individuals in the same situation. A given situation may activate (or suppress) crime liability for some individuals but not for others. Crime is a function of individual liability to commit crime and crime-activating properties of the situation. Crime is most likely to occur when an individual strongly predisposed to commit crime enters a situation with strong crime-activating properties.

\section{Individuals enter situations with varying degrees of readiness to commit crime}

Individuals may enter situations with formed intentions to commit crimes, they may succumb to temptations that are on offer, or they may be induced to commit crimes they had not hitherto contemplated. These states of readiness are not necessarily correlated with the strength of an individual's general potential to commit crime. For example, an individual who is generally predisposed to commit crime may enter a situation without any formed intention to offend at that time but be tempted or induced to do so.

\section{Situations affect an individual in multiple ways across moral,}

\section{affective, cognitive and behavioural domains}

Situations may activate/deactivate moral rules relating to a particular criminal act; activate/deactivate affective states promoting a particular criminal act; activate/deactivate cognitive processes - including perception, information processing and decision making - favouring criminal behaviour; activate/deactivate behavioural responses that constitute a criminal act. There is no reason why any given situation should consistently activate or deactivate moral rules, affective states, cognitive processes and behavioural responses in favour of or against a criminal act. 


\section{Individuals are only partially aware of the ways in which situations affect their behaviour}

Situations can influence individuals in ways that are subtle, below the level of conscious awareness, and outside their personal control. Much behaviour involves automatic cognitive processes, and a great deal of mental activity takes place below the level of conscious awareness. Individuals may respond to situations reflexively, emotionally, or as a matter of habit where little event-related reasoning takes place.

\section{Situations constrain what particular crimes an individual can} commit, in terms of the availability of crime opportunities and the resources he/she can draw on to commit crime

Only if the possibility of a given crime exists and the personal or physical resources are available to commit it does crime become an option. Some situations may exist where the possibility of crime has been removed or where no individual has the resources to commit a given crime however much they might like to do so. Crime opportunities and resources available for crime are liable to change.

The adoption of these ten tenets sends SCP in a different direction from RCP. They are intended to correct what are increasingly deemed implausible theoretical tenets for SCP research and practice. Moreover, the removal of the assumption within the ten tenets that RCP is an intrinsic part of SCP, sidesteps a commonly acknowledged weak assumption that has led to a widespread neglect or rejection of SCP by both researchers and practitioners. Most importantly, the elimination or residualisation of RCP as an essential element of SCP opens the way for new forms of research and practice that tease out and trade on 
situational measures which focus on cues that lie behind behaviour, which do not operate through rational decision-making or utility maximisation.

\section{CONCLUSION}

We have argued in this paper for a Lakatosian progressive problem-shift for the situational analysis of crime events and for situational crime prevention. Bolting on rational choice was intended to do the same at an earlier period, but has backfired. While ritually invoked in teaching and while functioning as an Aunt Sally for hostile critics, it has lost its ability to drive a research agenda or to inform thinking about new practical ways to address many crime problems. We have argued, therefore, that it has now become a fetter. Instead we have argued that in line with much other research in the social sciences a far wider range of causal mechanisms be drawn on in theory and practice.

What we would wish to retain is the broader situational approach: the concern with crime events rather than criminality, the focus on near causes rather than distant (so-called 'root') cases, the commitment to efforts to reduce crime by changing near causes including opportunities, a primary pragmatic interest in reducing crime harms in the short as well as long term, and inclusion of action research as a major way of learning about criminal events and their prevention. Hence this is not advocating a fundamental paradigm change. Indeed, far from it. Situational crime prevention comprises a relatively rare example on the social sciences where clear cumulation in theory, research and practice can be discerned (Tilley 2009). Our intention in writing this paper is to help ensure that that cumulation continues. 


\section{REFERENCES}

Becker, Gary. 1957. The Economics of Discrimination. Chicago: University of Chicago Press.

Blau. Peter M. 1964. Exchange and Power in Social life. New York: Wiley.

Bouhana, Noemie. 2013. The reasoning criminal vs. Homer Simpson: conceptual challenges for crime science. Frontiers in Human Neuroscience, 7: 682

Clarke, Ronald V.G. 1967. Seasonal and other environmental aspects of abscondings by approved school boys. British Journal of Criminology, 7: 195-206.

Clarke, Ronald V. 1980. "Situational” crime prevention: Theory and practice. British Journal of Criminology, 20: 136-147.

Clarke, Ronald V. 1992. Introduction. In Situational Crime Prevention: Successful Case Studies, ed. Ronald V Clarke, Albany NY: Harrow and Heston.

Clarke, Ronald V. 1997. Introduction. In Situational Crime Prevention: Successful Case Studies, ed. Ronald V Clarke, Albany NY: Harrow and Heston.

Clarke, Ronald V. 2005. Seven misconceptions of situational crime prevention. In Handbook of Crime Prevention and Community Safety, Nick Tilley, ed. Cullompton, UK: Willan.

Clarke, Ronald V. and Cornish, Derek B. 1985. Modeling offenders' decisions: A framework for research and policy. In Crime and Justice: An Annual Review of Research, Vol. 6, Michael Tonry and Norval Morris, eds. Chicago: University of Chicago Press.

Clarke, Ronald V. and Homel, Ross. 1997. A revised classification of situational crime prevention techniques. In Crime Prevention at the Crossroads, Steven P. Lab ed. Cincinnati, OH, Anderson. 
Clarke, Ronald V. and Martin, D.N. 1971. Absconding from Approved Schools. Home Office Research Study no. 12. London: H.M. Stationery Office. Coleman, James S. 1973. Mathematics of Collective Action. Chicago: Aldine Cornish, D.B. 1994. The Procedural Analysis of Offending and its Relevance for Situational Prevention. In Crime Prevention Studies volume 3, Ronald V. Clarke, ed. Monsey, N.Y.: Criminal Justice Press.

Cornish, Derek B. and Clarke, Ronald V. G. 1975. Residential Treatment and its Effects on Delinquency. HM London: Stationery Office.

Cornish, Derek B. and Clarke, Ronald V. 2003. Opportunities, precipitators and criminal decisions: A reply to Wortley's critique of situational crime prevention. In Theory for Practice in Situational Crime Prevention, Crime Prevention Studies volume 6, Martha Smith and Derek Cornish, eds. Monsey, NY: Criminal justice Press.

Cornish, D. B. and Clarke, R.V. (2008). The rational choice perspective, in R. Wortley and L. Mazerolle (eds) Environmental Criminology and Crime Analyses. Cullompton, UK: Willan.

Ekblom, P (2007). Making offenders richer, in G. Farrell, K. Bowers, S. Johnson and M. Townsley (ed.), Imagination for Crime Prevention: Essays in Honour of Ken Pease. Crime Prevention Studies 21: Monsey, N.Y.: Criminal Justice Press/ Devon, UK: Willan Publishing.

Ekblom, P., and Tilley, N. (2000). Going equipped. British Journal of Criminology,40: 376-398.

Elster, J. (2007) Explaining Social Behavior: More Nuts and Bolts for the Social Sciences. Cambridge: Cambridge University Press. 
Felson, R.B. (2005) Violence as instrumental behavior, in K. Kelloway, J. Barling, and J. Hurrell (eds) Handbook of Workplace Violence, Thousand Oaks: Sage Publications.

Gibbons, D. C. (1971). Observations on the study of crime causation. American Journal of Sociology, 262-278.

Haney, C., Banks, C. and Zimbardo, P. (1973). Interpersonal dynamics in a simulated prison, International Journal of Criminology and Penology 1: 6997.

Hayward, K. (2007). Situational crime prevention and its discontents: Rational choice theory versus the 'culture of now'. Social Policy and Administration, 41: $232-250$.

Homans, G.C. (1961) Social Behaviour: Its Elementary Forms. New York: Harcourt, Brace, and World.

Jeffery, C.R. (1971). Crime Prevention Through Environmental Design. Beverly Hill, CA: Sage.

Jeffery, C.R. (1977). Crime Prevention Through Environmental Design (2nd ed.). Beverly Hill, CA: Sage.

Kahle, L. R. (1984). Attitudes and Social Adaptation: A Person-Situation Interaction Approach. New York: Pergamon Press.

Kahneman, D., and Tversky, A. (1973). On the psychology of prediction. Psychological Review, 80, 237-251.

Katz, J. (2008). Seductions of Crime: Moral and Sensual Attractions in Doing Evil. New York: Basic Books.

Kuhn, T. S. (1962). The Structure of Scientific Revolutions. Chicago: University of Chicago Press. 
Lakatos, I. (1978). The Methodology of Scientific Research Programmes.

Cambridge: Cambridge University Press.

Laycock, G., and Pease, K. (2012). Ron and the Schiphol fly. In N. Tilley and G.

Farrell (eds) The Reasoning Criminologist: Essays in Honour of Ronald V. Clarke, London: Routledge.

Mayhew, P., Clarke, R. V., Sturman, A., and Hough, J. M. (1976). Crime as

Opportunity. Home Office Research Study. No. 34. London, Home Office.

Milgram, S. (1974) Obedience to Authority: An Experimental View. New York: Harper and Row.

Mischel, W. (1968). Personality and Assessment. New York, NY: Wiley.

Mischel, W. (2004). Toward an integrative science of the person. Annual Review of Psychology, 55, 1-22.

Mischel, W., and Shoda, Y. (1995). A cognitive-affective system theory of personality: reconceptualizing situations, dispositions, dynamics, and invariance in personality structure. Psychological Review, 102: 246.

Nee, C., and Ward, T. (2014). Review of expertise and its general implications for correctional psychology and criminology. Aggression and Violent Behavior.

Newman, 0. (1972). Defensible Space: Crime Prevention Through Urban Design. New York: MacMillan.

Popper, K.R. (1959). The Logic of Scientific Discovery. London: Hutchinson and Co.

Ross, L., and Nisbett, R. E. (2011). The Person and the Situation: Perspectives of Social Psychology. Pinter and Martin Publishers.

Savage, L. (1954). The Foundations of Statistics. New York: Wiley. 
Sidebottom, A., and Tilley, N. (Forthcoming). Situational prevention and offender decision making. In W. Bernasco, H. Elffers and J-L Van Gelder (eds) Oxford Handbook of Offender Decision Making. Oxford: Oxford University Press.

Simon, H.A. (1955). A behavioral model of rational choice. Quarterly Journal of Economics, 69: 99-118.

Simon, H.A. (1957). Models of Man. New York: Wiley.

Sinclair, I. A. C., and Clarke, R. V. G. (1973). Acting-out behaviour and its significance for the residential treatment of delinquents. Journal of Child Psychology and Psychiatry, 14: 283-291.

Tilley, N. (2009) Crime Prevention. London: Routledge.

Trasler, G. (1986). Situational crime control and rational choice: A critique. In K. Heal and G. Laycock (eds.), Situational Crime Prevention: From Theory Into Practice. London: Home Office Research and Planning Unit.

Van Gelder, J. L., Elffers, H., Reynald, D., and Nagin, D. S. (2014a). Affect and Cognition in Criminal Decision Making. London: Routledge.

Van Gelder, J. L., Elffers, H., Reynald, D., and Nagin, D. S. (2014b). Affect and cognition in criminal decision making: Between rational choice and lapses of self control. In J.L. Van Gelder, H. Elffers, D. Reynald, and D.S. Nagin (eds) Affect and Cognition in Criminal Decision Making. London: Routledge.

von Neumann, J., Morgenstern, O. (1944). Theory of Games and Economic Behavior. Princeton: Princeton University Press.

Wikström, P. O. H., and Treiber, K. (2015). Situational Theory: The Importance of Interactions and Action Mechanisms in the Explanation of Crime. The Handbook of Criminological Theory, 4, 415. 
Wortley, R. (1997). Reconsidering the role of opportunity in situational crime prevention. In G. Newman, R. Clarke and S. Shoham (eds). Rational Choice and Situational Crime Prevention (pp. 65-82). Aldershot, Hampshire: Ashgate.

Wortley, R. (2001). A classification of techniques for controlling situational precipitators of crime. Security Journal, 14(4): 63-82

Wortley, R. (2012). Exploring the Person-Situation Interaction in Situational Crime Prevention. In N. Tilley and G. Farrell (eds) The Reasoning Criminologist: Essays in Honour of Ronald V. Clarke, London: Routledge.

Wortley, R. (2013). Rational Choice and Offender Decision Making: Lessons from the Cognitive Sciences. In B. Leclerc and R. Wortley (eds), Cognition and Crime: Offender Decision-Making and Script Analyses. London: Routledge. Zimbardo, P. (2007). The Lucifer Effect. New York: Random House. 